\title{
Enzymatic polymerization of catechol under high-pressure homogenization for the green coloration of textiles
}

\author{
Jing $\mathrm{Su}^{\mathrm{a}}{ }^{\mathrm{b}}$, Jennifer Noro ${ }^{\mathrm{b}}$, Jiajia Fu ${ }^{\mathrm{a}}$, Qiang Wang ${ }^{\mathrm{a}}$, Carla Silva ${ }^{\mathrm{b},{ }^{* *} \text {, }}$ \\ Artur Cavaco-Paulo ${ }^{\text {a, b, * }}$ \\ a International Joint Research Laboratory for Textile and Fiber Bioprocesses, Jiangnan University, Wuxi 214122, China \\ ${ }^{\mathrm{b}}$ Centre of Biological Engineering, University of Minho, Campus de Gualtar, 4710-057 Braga, Portugal
}

\section{A R T I C L E I N F O}

\section{Article history:}

Received 4 May 2018

Received in revised form

23 July 2018

Accepted 20 August 2018

Available online 21 August 2018

\section{Keywords:}

Catechol

Laccase

High-pressure homogenization

Oxidation

Coloration

\begin{abstract}
A B S T R A C T
Laccase from Myceliophthora thermophila was used to catalyze the polymerization of catechol under high-pressure homogenization for the green coloration of textile substrates. The oxidation reactions were conducted using different forms of laccase, namely native laccase, PEGylated laccase and PEGylated laccase immobilized onto an epoxy resin. The three enzyme forms were deposited inside a polyester fabric bag during the experiments. The amount of polymer obtained was similar when using the three enzyme forms and its dispersion in water/DMSO mixture lead to powder particles of about 30-60 nm. The immobilized and PEGylated enzymes lead to poly(catechol) with 13 and 10 units, respectively, while the native form gave rise to shorter polymers $(\mathrm{DP}=8)$. We have shown that the oxidation of catechol conducted under high-pressure homogenization can be an efficient methodology for the in situ coloration of textiles. The polymers produced by this methodology stained strongly the textile container, revealing this experimental set-up as a promising greener coloration/coating methodology involving milder conditions than the normally used in textile processes.
\end{abstract}

(c) 2018 Published by Elsevier Ltd.

\section{Introduction}

Phenolic compounds, such as catechol, are released to the environment from a variety of industrial sources since they are often used as industrial reagents in the production of rubber, dyes, pesticides, colors, plastics, pharmaceuticals, and cosmetics (Tušek et al., 2017). When organic compounds like catechol are released into the environment, they can accumulate in the soil, groundwater and surface water, and therefore become an issue of great environmental concern. The presence of these potentially toxic chemicals may be able to transform into teratogenic or carcinogenic agents to life (Aghapour et al., 2013; Cheng et al., 2016, 2018; Cohen et al., 2009; Liu et al., 2017). The increased demand of the industry to develop environmentally friendly methodologies lead to the development of enzymatic processes for its pollutant removal from wastewater (Shinji et al., 1993; Tušek et al., 2017).

\footnotetext{
* Corresponding author. International Joint Research Laboratory for Textile and Fiber Bioprocesses, Jiangnan University, Wuxi 214122, China.

** Corresponding author.

E-mail addresses: carla.silva@ceb.uminho.pt (C. Silva), artur@deb.uminho.pt (A. Cavaco-Paulo).
}

Laccase-catalyzed polymerization has received much attention from researchers in the last decades due to its ability to oxidize both phenolic and non-phenolic compounds as well as highly recalcitrant environmental pollutants, making it useful for applications on several biotechnological processes (Riva, 2006; Rodríguez Couto and Toca Herrera, 2006). Laccases, a family of multi-copper containing oxidoreductases, are probably one of the most promiscuous enzymes considering their excellent catalytic properties. They are capable of oxidizing a wide range of different substrates with or without mediators under mild conditions, and for these reasons several researchers have been applying them on the polymer synthesis (Jeon et al., 2012; Kunamneni et al., 2008; Witayakran and Ragauskas, 2009). As typical laccase substrates, phenols, namely catechol, and its derivatives, can generate various functional polymers based on diverse monomers, which may be applied in several fields like medicine, cosmetics, food and textiles. During synthesis, laccases are known to provide a unique alternative to organic synthesis compared with conventional chemical-catalyzed synthetic processes. The oxidation of catechol using laccase as catalyst has been studied. Saha et al. investigated a two-step treatment method for the removal of phenol, benzenediols, and an equimolar mixture of phenol and benzenediols from water and demonstrated 
that the proposed enzymatic method is a viable alternative means to remove phenol and benzenediols from industrial wastewaters (Saha et al., 2011). Tušek et al. tested two different methods to immobilize laccase from Trametes versicolor and compared them for the catechol polymerization using different reactors (Tušek et al., 2017). They found the successful catechol oxidation using immobilized laccase in different reactor systems, batch and continuous, micro and macro size.

Different reactors have been explored to proceed the enzymecatalyzed reactions (Gupta and Roy, 2004; Henriksson et al., 2007; Shah and Gupta, 2008). Generally, water bath is the most common device used to promote mechanical agitation and improve the mass transport effects. However, the absence of external stimulus reveal low polymerization yields mainly due to inefficient agitation and thus low mass transport is achieved (Zerva et al., 2016). These results lead the researchers to investigate the use of different devices able to promote higher levels of conversion. They found that when ultrasound devices were applied, cavitation effects enhanced the transport of substrate molecules to the enzyme improving catalysis and accelerating the reactions (DelgadoPovedano and Luque de Castro, 2015; Lobo et al., 2013; Yachmenev et al., 2009; Yachmenev et al., 2002). Several works have been reporting enzyme catalysis assisted by high-pressure homogenization (HPH) (Gonçalves et al., 2014; Martins et al., 2015), and their results reveal HPH as a promising method to improve the enzyme application under cavitation effects. Highpressure homogenization, as well as ultrasound, are known to produce cavitation, which may accelerate reactions and increment the mass transport phenomena (Gall et al., 2016; Romanski et al., 2011). Until now and from our knowledge, the use of HPH on the polymer synthesis is still poorly explored.

In previous studies, we conducted the catechol polymerization with laccase from Myceliophthora thermophila using different apparatus, namely a water bath, an ultrasonic bath and a highpressure homogenizer (Su et al., 2018). The results obtained showed higher conversion yields and polymerization degrees when both high-energy reactors were used, compared to the water bath reactor. Molecular dynamic simulations performed also demonstrated that under these conditions the enzyme presented a more open active site which we consider the main factor for the higher substrate accessibility to the enzyme therefore favoring the production of longer polymers. High-pressure homogenization was thus considered as a promising technique for catechol polymerization.

In this study, our goal was to evaluate the catalytic ability of different forms of laccase to polymerize catechol under highenergy/pressure environments. The catalysis was thus conducted using native laccase, PEGylated laccase and laccase immobilized onto an epoxy resin (Epoxy-PEGylated laccase) under highpressure homogenizer (HPH) (Fig. 1). In this study, the nonsoluble enzyme form was contained within a polyethylene terephthalate (PET) bag, as well as the other forms for control purposes. The objective was to constrain the immobilized enzyme movement along the machine and allow only the liquid solution to recirculate. The polymerization was followed during time by UV-Vis spectra analysis to monitor colour change. The produced polymers were characterized by weight measurement, ${ }^{1} \mathrm{H}$ NMR, and TGA. The particle size of the polymer powders was analyzed by dynamic light scattering analysis. We aim with this work to evaluate the potentialities of the high-pressure homogenization as energy source for the enzymatic-catalysis reactions with different laccase forms and explore the possibilities to obtain polymers with coloring performance via a green methodology. Generally, fabric dyeing processes imply the use of extreme conditions like high temperatures and/or highly acidic or alkaline pHs. Polyphenolic components from laccase reactions are produced at milder conditions and could be used for green coloration.

\section{Materials and methods}

\subsection{Materials}

\subsubsection{Enzyme and reagent sources}

Laccase from Myceliophthora thermophila (Novozymes A/S, batch number: OMN07012) was supplied by Novozymes, Denmark. Catechol, poly(ethylene glycol) methyl ether and sodium carbonate were purchased from Sigma Aldrich, Spain. Deuterated dimethyl sulfoxide was obtained by Cortecnet, France.

\subsection{Methods}

\subsubsection{PEGylation of laccase}

Laccase from Myceliophthora thermophila was PEGylated as previously reported (Su et al., 2017) using the procedure of Daly et al. (2005). Briefly, $14.0 \mathrm{~mL}$ of $12 \mathrm{mg} / \mathrm{mL}$ laccase were reacted with $20 \mathrm{kDa}$, poly(ethylene glycol) methyl ether at pH 5.0 phosphate solution $100 \mathrm{mM}$ with $20 \mathrm{mM}$ sodium cyanoborohydride. A control reaction without $\mathrm{m}$ PEG was also conducted in every experiment. The reactions were stirred rapidly for $17 \mathrm{~h}$ at $4{ }^{\circ} \mathrm{C}$. After 10 min of mixing, the reactants were completely dissolved, and an aliquot (namely time $0 \mathrm{~h}$ ) was taken, as well as at each time point of reaction. These samples were ultrafiltrated, and washed several times with water, using a $30 \mathrm{kDa}$ cellulose membrane mounted in an ultrafiltration apparatus, to separate the free PEG. Afterwards the final solution was freeze-dried.

\subsubsection{Immobilization of PEGylated laccase onto epoxy resin supports}

The immobilization of PEGylated laccase onto epoxy methacrylate resins (Purelite Lifetech ECR enzyme immobilization resins: 300-600 §) was conducted as follows: $2 \mathrm{mg} / \mathrm{mL}$ PEGylated laccase in $0.5 \mathrm{M}$ acetate buffer ( $\mathrm{pH} 5.0$ ) were mixed with epoxy methacrylate $(50 \mathrm{mg} / \mathrm{mL})$ and then stirred for $48 \mathrm{~h}$ at $4{ }^{\circ} \mathrm{C}$. The powder was then washed several times with water by centrifugation and dried under vacuum.

\subsubsection{Evaluation of enzyme activity and stability}

The effect of high-pressure on the activity and stability of native laccase, PEGylated laccase and Epoxy-PEGylated laccase, was evaluated. For this, the three forms of laccase were incubated under the same conditions used for catechol polymerization: $100 \mathrm{U} / \mathrm{mL}$ enzyme were incubated in acetate buffer $(\mathrm{pH}=5)$ at $40^{\circ} \mathrm{C}$ for $3 \mathrm{~h}$, using a high-pressure homogenizer. The enzymes were exposed for longer time in order to ensure the accurate stability during time. Aliquots of enzyme solution were taken at different periods of incubation and the activity of laccase was measured against ABTS according to the methodology described by Childs and Bardsley (1975).

\subsubsection{Enzyme-assisted polymerization of catechol}

Catechol polymerization was processed by incubating $50 \mathrm{mM}$ of monomer in different solutions: a) $100 \mathrm{U} / \mathrm{mL}$ native laccase and b) 100 U/mL PEGylated laccase, c) 100 U/mL Epoxy-PEGylated laccase, in acetate buffer $(\mathrm{pH}=5)$. The immobilized enzyme was confined in a polyethylene terephthalate (PET) bag and placed in the sample receptor of the high-pressure homogenizer. For control reasons, the other enzyme forms were also placed inside the PET bag. Afterwards the catechol solution was added and the homogenization proceed for $2 \mathrm{~h}$ (corresponding to 360 homogenization cycles). During the reaction, the top of the feed port was covered with a 


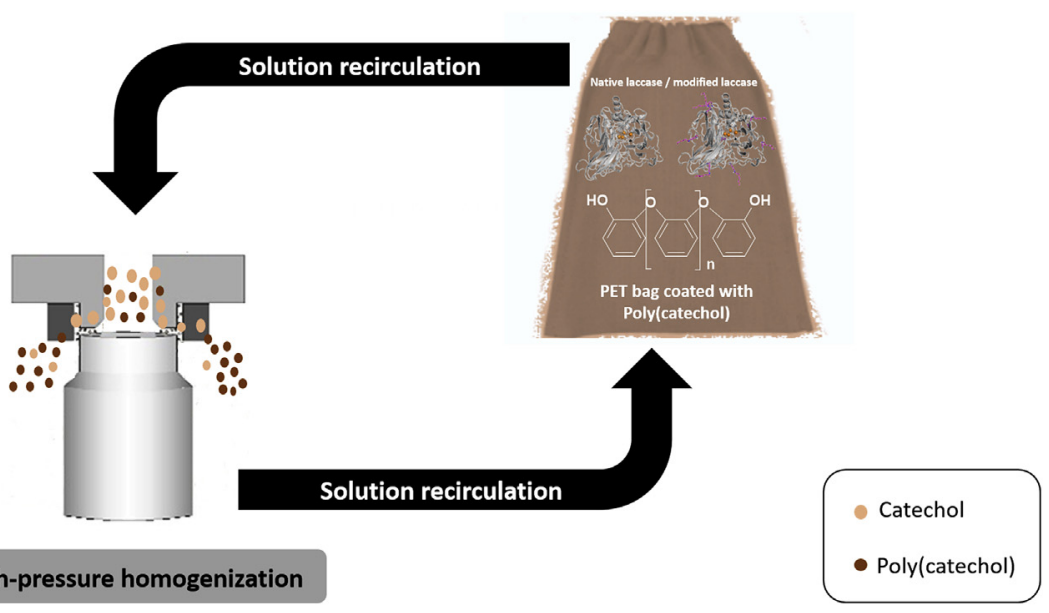

Fig. 1. Representation of the polymerization of catechol with native and modified laccases under high-pressure homogenization using a PET bag as enzyme container.

parafilm with tiny holes to allow the air oxygen entrance without extra oxygen supply. The starting temperature was set to $40^{\circ} \mathrm{C}$ and the temperature was monitored during processing to follow the inherent increase during high-energy device processing. Next the polymer powder was collected from the HPH device by dissolution with dimethyl sulfoxide to solubilize the insoluble polymers and posteriorly dried under vacuum for ${ }^{1} \mathrm{H}$ NMR analysis.

\subsection{5. ${ }^{1} \mathrm{H} N M R$}

${ }^{1} \mathrm{H}$ NMR spectra were acquired in a Bruker Avance III 400 ( $400 \mathrm{MHz}$ ). DMSO-d6 was used as deuterated solvent, using the peak solvent as internal reference.

\subsubsection{Determination of total content of free $\mathrm{OH}$ groups}

The total content of free $\mathrm{OH}$ groups before and after polymerization was performed using the Folin-Ciocalteu spectrophotometric method. The monomer and polymer solutions dissolved in DMSO $(100 \mu \mathrm{L})$ were added to the mixture of Folin-Ciocalteu reagent $(500 \mu \mathrm{L})$ and distilled water $(6 \mathrm{~mL})$, and the mixture was shaken for $1 \mathrm{~min}$. Then $\mathrm{Na}_{2} \mathrm{CO}_{3}$ solution $(15 \%, 2 \mathrm{~mL}$ ) was added to the mixture and shaken for $1 \mathrm{~min}$. Later the solution was brought up to $10 \mathrm{~mL}$ by adding distilled water. After $2 \mathrm{~h}$, the absorbance at $750 \mathrm{~nm}\left(25^{\circ} \mathrm{C}\right)$ was measured. The total content of free $\mathrm{OH}$ was assessed by plotting a gallic acid calibration curve (from 1 to $1500 \mu \mathrm{g} / \mathrm{mL}$ ). The equation of the gallic acid calibration curve was $\mathrm{A}=0.2977 \mathrm{c}+0.0368$, and the correlation coefficient was $\mathrm{r}^{2}=0.9988$.

\subsubsection{Thermogravimetric analysis (TGA)}

Thermogravimetric analysis (TGA) was carried out in a Perkin Elmer TGA 4000 equipment. Calibration was performed with metals, such as Nickel, Alumel and Perkalloy, based on their Curie Point Reference. All the analyses were performed with a $6 \mathrm{mg}$ sample in aluminum pans under a dynamic nitrogen atmosphere between 100 and $700^{\circ} \mathrm{C}$. The experiments were run at a scanning rate of $20^{\circ} \mathrm{C} / \mathrm{min}$.

\section{Results and discussion}

\subsection{Effect of chemical modifications on enzyme's catalytic activity}

PEGylation and immobilization processes are known to conduct to more stabilized catalysts however reducing their specific activity (Datta et al., 2013; Mayolo-Deloisa et al., 2015). Herein, one could observe that after PEGylation and immobilization process a ratio of activity among native laccase, PEGylated laccase and EpoxyPEGylated laccase of (1: 0.7: 0.55) was observed, revealing an activity loss after the chemical modification process, as also confirmed previously by others (Mayolo-Deloisa et al., 2015).

\subsection{Poly(catechol) production and characterization}

\subsubsection{UV/visible spectra monitoring during catechol polymerization}

During laccase-assisted polymerization of catechol under highpressure homogenization, all the reaction mixtures changed colour from colourless to dark brown, and the UV-Vis spectra was recorded to follow the reaction (Fig. 2). From data obtained, it can be seen all spectra present a typical peak around $300 \mathrm{~nm}$ which increases in intensity after polymerization due to new molecular arrangement and polymer formation. The spectra of catechol incubated with enzymes present a new peak at around $430 \mathrm{~nm}$ confirming polymerization.

Generally an increase in the UV-Vis absorption intensity indicates a greater degree of $\pi$-conjugation correlated with the occurrence of polymerization (Jha and Halada, 2011), and this increase is directly related with the amount of soluble poly- or

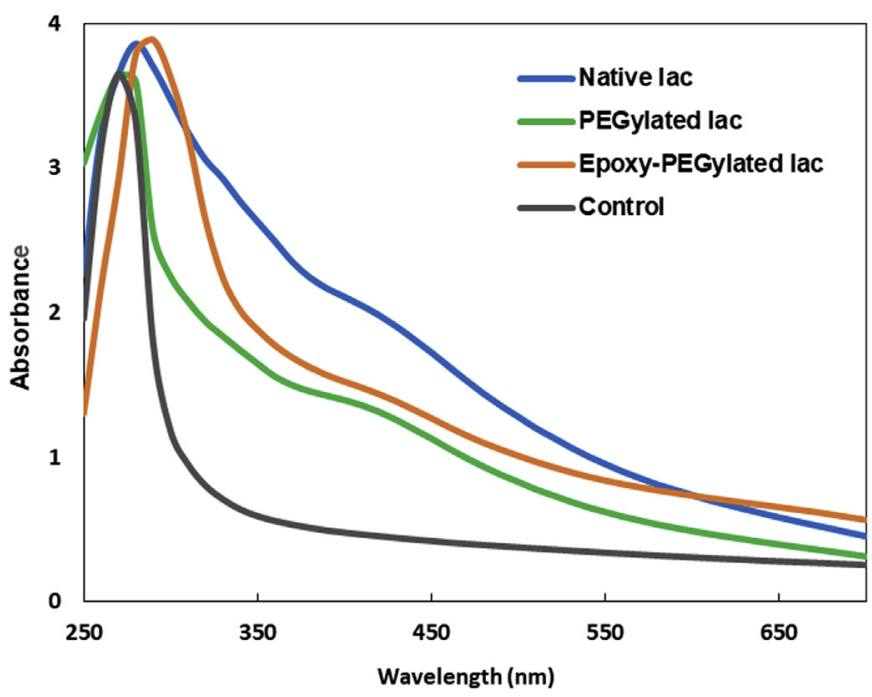

Fig. 2. UV/Visible spectra of poly(catechol) polymerized by different enzyme forms using $\mathrm{HPH}$; the spectra was acquired after $2 \mathrm{~h}$ of incubation. 
oligomers, which is remarkable higher for samples polymerized in the presence of native laccase in this study. However, differences in $\mathrm{UV}$-Vis spectra are related with the amount of soluble poly- or oligomers and are not attributed to the precipitate (Zerva et al., 2016). Precipitates with darker colour in the reaction solution correspond to insoluble polymers formed and cannot be quantified by UV-Vis spectra, being therefore quantified by weight measurement. Besides this, the polymers coated onto PET fabric were also quantified by weighting and considered for the total amount of polymer produced and yield of polymerization (Table 1). The data obtained reveal higher reaction yield when PEGylated laccase is used as catalyst. These findings are in accordance with our previous findings which reveal that PEGylation of laccase greatly enhances catechol polymerization, and the molecular dynamic simulations suggested that PEG serves as template forming a complex with the newly formed polymer, pushing the reaction forward (Su et al., 2017).

As confirmed by others, UV/Visible data reveal that laccase catalysis of catechol assisted by high-pressure homogenization provide a mild route to produce polymers and may offer a green alternative to the environmentally unfriendly, costly and less specific physico-chemical methods (Aktaş et al., 2003; Aktas and Tanyolac, 2003; Faure et al., 2013; Kudanga et al., 2011). Moreover the toxicity reduction is favored since the soluble and toxic monomer is converted into a polymer powder in general lesser toxic.

\subsubsection{Enzyme stability during enzymatic oxidation process}

All enzyme forms used herein were subjected during processing to the high-pressure homogenization heating conditions which might affect their catalytic performance. To predict the effect of high-pressure homogenization on enzyme activity and stability, an experiment was conducted using the same conditions as applied for catechol polymerization without addition of monomer. The activity of the enzyme was evaluated during time by evaluation at different periods of incubation. According to Fig. 3, as the processing time increased, a decrease of activity is observed for all the enzymes tested, however, displaying a different decay. For native laccase it is evident a deep decrease of the activity on the first periods of incubation. The residual activity was maintained only in around 55\% after $2 \mathrm{~h}$ of incubation. The PEGylated and immobilized/PEGylated laccase forms, showed a different behavior, a slow drop of the activity was verified during time and the residual activity after $2 \mathrm{~h}$ of incubation remained at around $75 \%$ and $73 \%$, respectively. We might speculate that the different deactivation behavior observed is probably due to the stabilization effect of the PEG and of the immobilization which, in the case of the modified enzymes, delayed the enzyme deactivation (Kozlowski and Milton Harris, 2001; Yang et al., 2011).

Table 1

Yield of polymerization of catechol using different enzyme forms.

\begin{tabular}{lllll}
\hline & $\begin{array}{l}\text { Weight of } \\
\text { polymer } \\
\text { coated } \\
\text { onto fabric } \\
(\mathrm{mg})\end{array}$ & $\begin{array}{l}\text { Weight of } \\
\text { polymer } \\
\text { powder } \\
\text { recovered } \\
\text { from } \\
\text { solution }(\mathrm{mg})\end{array}$ & $\begin{array}{l}\text { Total weight } \\
\text { of polymer } \\
(\mathrm{mg})\end{array}$ & $\begin{array}{l}\text { Yield of } \\
\text { reaction }\end{array}$ \\
& & 22.8 & 30.4 & 60.8 \\
\hline $\begin{array}{l}\text { Native laccase } \\
\begin{array}{c}\text { PEGylated } \\
\text { laccase }\end{array}\end{array}$ & 7.6 & 27.1 & 36.2 & 72.8 \\
$\begin{array}{c}\text { Epoxy-PEGylated } \\
\text { laccase }\end{array}$ & 7.4 & 24.1 & 31.5 & 63.0 \\
\hline
\end{tabular}

${ }^{\mathrm{a}}$ Yield of reaction $=$ (weight of polymer recovered from solution + weight of polymer coated onto fabric)/total weight of monomers) $* 100 \%$.

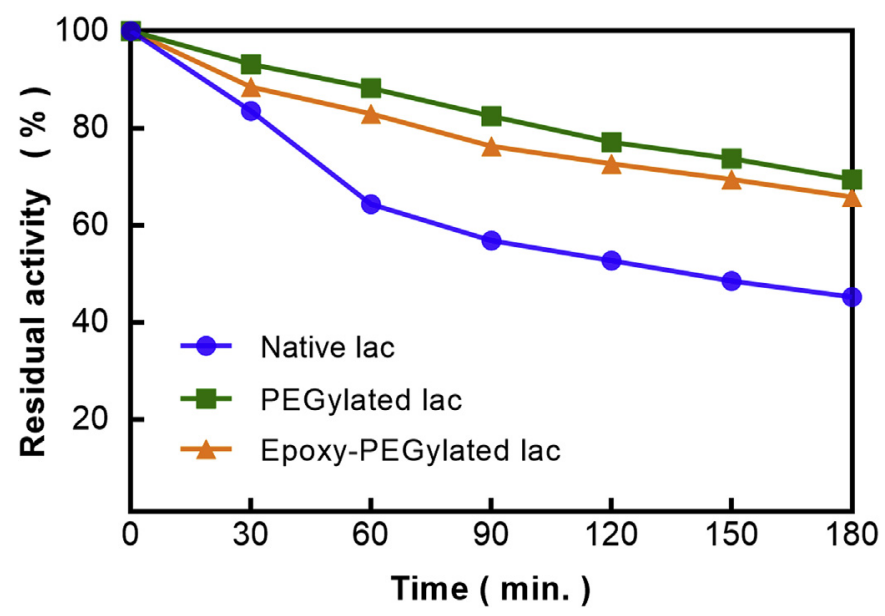

Fig. 3. Residual activity (\%) of all enzyme forms when incubated in the same conditions as the used for catechol polymerization under high-pressure homogenizer.

\subsection{3. ${ }^{1} \mathrm{H}$ NMR characterization of poly(catechol)}

Fig. 4 shows the spectrum of catechol and poly(catechol) after polymerization. As it can be seen by ${ }^{1} \mathrm{H}$ NMR data, the aromatic peaks of the polymers suffer a chemical shift from $\delta_{\mathrm{H}} 6.58$ and 6.72 to $\delta_{\mathrm{H}} 6.88$ and $6.96 \mathrm{ppm}$. No other peaks are observed in the spectra, and it is noteworthy that all the powder is completely soluble in the DMSO-d6 for analysis. The $\mathrm{OH}$ peak of catechol is observed at $\delta_{\mathrm{H}} 8.8 \mathrm{ppm}$ as a singlet (proton a). In the polymers spectra, this peak disappears, while a small singlet is observed at $\delta_{\mathrm{H}}$ $8.48 \mathrm{ppm}$, which is assigned as the terminal $\mathrm{OH}$ of the polymers (proton $\mathrm{d}$ ). The patterns turn to be more complex in the polymers, but the calculation of the coupling constants is still possible. Catechol has coupling constants of $J=6.0$ and $3.6 \mathrm{~Hz}$, corresponding to the orto and meta coupling constants, respectively. The same coupling constants were obtained for the polymers obtained using the three different laccase forms, suggesting that polymerization reaction occurred via hydroxyl groups in all cases.

COSY bidimensional spectra shows the correlation between the aromatic protons of poly(catechol) (Fig. 4C). The pattern of the peaks (two doublet of doublets), and the COSY analysis corroborates the previous proposed structure, which suggests that the polymerization of catechol occurs by the oxygen atoms.

To confirm the role of different laccase forms on the polymerization, the amount of oxyphenylene units was estimated by measuring the total content of free $\mathrm{OH}$ in all the mixtures after reaction (Table 2). Folin-Ciocalteau method measured the total $\mathrm{OH}$ after catechol polymerization and the values are normalized considering the total content of free $\mathrm{OH}$ of catechol as $1(100 \%)$. From Table 2, it can be depicted a decrease of the total free $\mathrm{OH}$ after catechol polymerization in the presence of PEGylated laccase being more pronounced for samples polymerized by EpoxyPEGylated laccase. As the content of $\mathrm{OH}$ groups decrease as more chains of oxyphenylene are present, confirming higher degrees of polymerization, which is accordance with the ${ }^{1} \mathrm{H}$ NMR results. The average polymerization degrees are 8, 10 and 13, when native laccase, PEGylated laccase and Epoxy-PEGylated laccase were applied, respectively. From this data it was possible to infer the role of enzyme form on the polymerization degree. One can establish that using the later PEGylated laccase and Epoxy-PEGylated laccase higher DP and higher amount of poly(catechol) is obtained, confirming our previous findings (Su et al., 2018) (Table 1). The green, high-energy efficient and low cost methodology (Jonsson, 2005) applied, high-pressure homogenization, played however a crucial role on improving the 


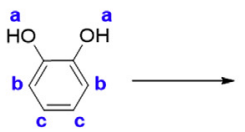

A)

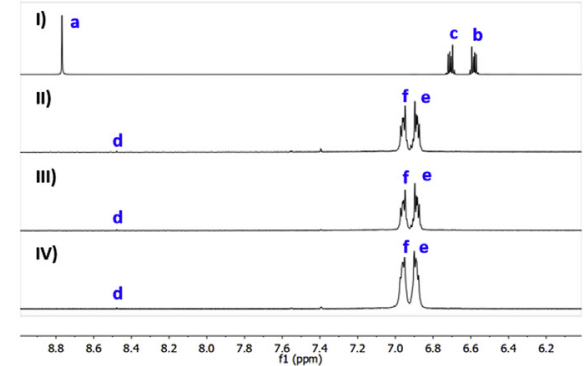

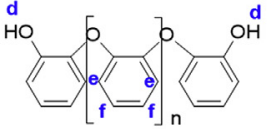

B)

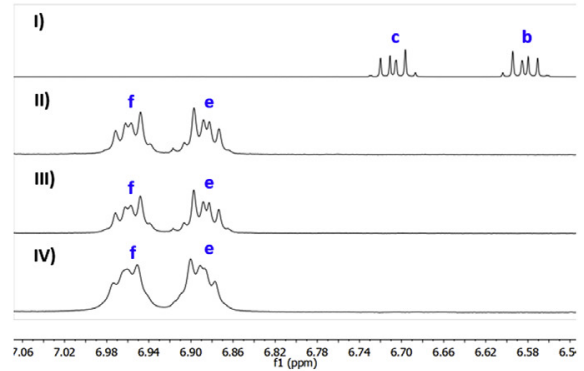

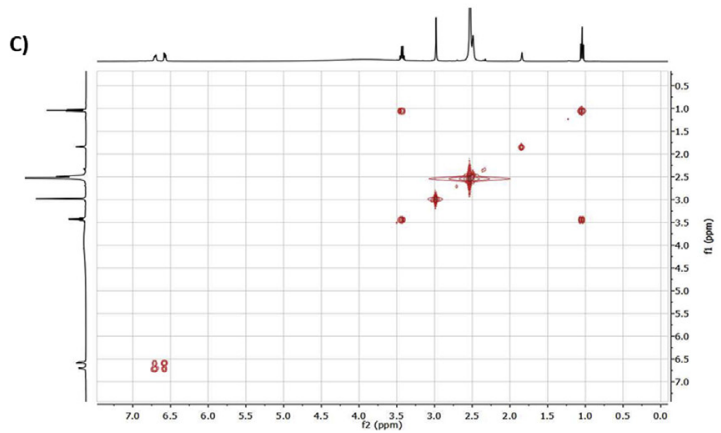

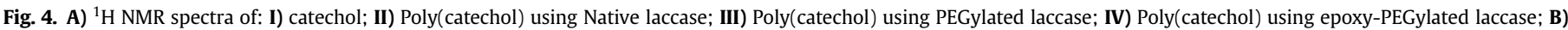
expansion of the ${ }^{1} \mathrm{H}$ NMR spectra in A); C) COSY spectra of poly(catechol) using epoxy-PEGylated laccase as catalyst (recorded in DMSO-d6).

Table 2

Degree of polymerization (DP) calculated by ${ }^{1} \mathrm{H}$ NMR; particle size of polymer powders (polydispersity; count rate) and total content of free OH groups.

\begin{tabular}{|c|c|c|c|c|c|}
\hline Poly-catechol & $\begin{array}{l}\text { Degree of polymerization } \\
\text { (DP) by }{ }^{1} \mathrm{H} \text { NMR }\end{array}$ & Size $(\mathrm{nm})(50 \% \mathrm{H} 2 \mathrm{O} / 50 \% \mathrm{DMSO})$ & Polydispersity (PDI) & Count rate & $\begin{array}{l}\text { Total content of free } \\
\mathrm{OH} \text { (catechol as } 1.0 \text { ) }\end{array}$ \\
\hline Native laccase & 8 & $39.26 \pm 0.42$ & 0.11 & 474.1 & 0.4849 \\
\hline PEGylated laccase & 10 & $55.77 \pm 1.60$ & 0.11 & 170.8 & 0.3634 \\
\hline Epoxy-PEGylated laccase & 13 & $61.86 \pm 2.11$ & 0.17 & 263.3 & 0.3215 \\
\hline
\end{tabular}

polymerization of catechol. Comparing with previous findings using native laccase in a high-pressure homogenizer, we found herein an increase of the DP from 6 to 8. Moreover, the poly(catechol) polymerized by PEGylated and epoxy-PEGylated laccases suffered an increase of the final DP when homogenization is applied, in comparison with processing in a water bath (Su et al., 2017). Hydrodynamic cavitation, the type of cavitation inherent to the high-pressure homogenizer, is generated by the flow of liquid through a simple geometry such as venture tubes or orifice plates under controlled conditions. When the pressure at the throat falls below the vapor pressure of the liquid, the liquid flashes, generating a number of cavities, which subsequently collapse when the pressure recovers downstream of the mechanical constriction (Gogate and Pandit, 2000). These liquid jets activate the solid catalyst and increase the mass transfer to the surface by disruption of the interfacial boundary layers as well as dislodging the material occupying the active sites (Gogate et al., 2006). In comparison with acoustic cavitation, this type of technology is more energy efficient and low processing costs are associated. Moreover, the use of a biological catalyst replacing the chemicals generally used, provide a green approach for the catechol detoxification through polymerization (Yang et al., 2017).

The use of a PET fabric bag as enzyme container might also be significant to improve the polymerization of catechol. It was not expectable a high affinity of the newly polymers within the surface of PET fabric due to a lack of bond formation between the polymers and the PET fiber. However, we can speculate that the pairing of the aromatic part of the newly formed polymers with the aromatic chains of PET (stacking interaction) might favor the polymerization and increase the amount of polymer at the surface of the support.

The effect of high-pressure homogenization on the particle size of the polymers obtained was also evaluated. Our previous findings reveal particle size of poly(catechol) catalyzed by native laccase, PEGylated laccase and Epoxy-PEGylated laccase using a water bath of $135.70 \pm 0.68 \mathrm{~nm}, \quad 155.90 \pm 2.35 \mathrm{~nm}$ and $162.70 \pm 1.56 \mathrm{~nm}$, respectively (Su et al., 2017). The use of hydrodynamic cavitation for catechol polymerization promoted a significant decrease of poly(catechol) particle's size, as presented in Table 2. Small, narrow and monodisperse polymer populations, in the range of $30-60 \mathrm{~nm}$, are obtained for all the enzyme forms used. As confirmed by others (Romanski et al., 2011), the high-pressure homogenizer operated at high dynamic pressure is effective in reducing the particle size of the polymers. The combination of shear, grinding and cavitation, promote the collapse on the surface, particularly of powders, producing enough energy to cause fragmentation and thus reducing the final achievable particle size of the polymers (Romanski et al., 2011). 


\subsubsection{Thermal properties of poly(catechol)}

The thermal properties of the synthesized poly(catechol) were investigated by thermogravimetric analysis (TGA). Depending on the conditions of polymerization, differences in poly(catechol) TGA thermal behavior can be found in the literature (Zerva et al., 2016). In our work, the substrate catechol only shows one-step decomposition, losing all the weight from 100 to $230{ }^{\circ} \mathrm{C}$ (shown in Fig. A.1). Herein, poly(catechol) synthesized by different laccase forms exhibited two distinct stages of weight loss, at around $120^{\circ} \mathrm{C}$, corresponding to $5 \%$ of weight loss, and at around $400{ }^{\circ} \mathrm{C}$, corresponding to $50 \%$ of weight loss (Table 3 ). Like others previously reported, the new polymers formed presented a very slow degradation rate above $200{ }^{\circ} \mathrm{C}$ (Zerva et al., 2016). We also find a residue of around $40 \%$, namely when modified enzymes were used, up to $700{ }^{\circ} \mathrm{C}$, which is also in accordance with previous data reported (Dubey et al., 1998; Nabid et al., 2010). Compared with catechol, which presented a vestigial amount of residue up to $700{ }^{\circ} \mathrm{C}$, the new polymers formed demonstrated high stability to thermal degradation, especially when polymerized by the modified forms of laccase, PEGylated or epoxy-PEGylated laccase under high-pressure homogenization.

\subsection{Fabric coloration with poly(catechol)}

The use of laccase to synthesize colorants "in situ", from aromatic compounds such as phenols, has been presenting as an efficient way for textiles dyeing at green and mild reaction conditions of $\mathrm{pH}$, temperature and chemical reduction or elimination. Environmental issues have been led to an extensive research on the enzymatic dyeing of protein and cotton fibers (Diaz Blanco et al., 2009; Kim et al., 2007; Li et al., 1999). However, due to their composition and hydrophobicity, polyester fibers are still poorly explored on this context. Herein, when using a PET bag as enzyme container for the catechol polymerization we found that the newly polymers produced were covering the fiber surface and this coating was stable after washing (Fig. 5). Comparing with control sample (catechol incubated with buffer using the same high-pressure conditions, without laccase), the PET fabric samples containing poly(catechol) polymerized by native, PEGylated and epoxy-PEGlaccase presented higher coloration. Spectral data reveal different coloration for the different enzymes used. Higher coloration was obtained when using native laccase, followed by PEGylated and epoxy-PEG-laccase. As expected, the modified enzymes gave rise to lower coloration levels since part of the polymers produced by these forms are insoluble and would hardly be attached to the PET surface. Low polymer particles obtained by using native laccase were more prone to colorize the PET fabric surface. It is noteworthy that the particle size was determined by using a mixture of water/ DMSO after polymer recover at the end of the process. We may speculate higher polymer particle size during polymerization with modified enzymes in buffer (data not shown), which hinder a homogeneous covering of the fabric surface.

Table 3

Thermal performance of catechol and poly(catechol) ( $\mathbf{T}_{\mathbf{5} \%}$ : temperature where polymers reach $5 \%$ of weight loss; $\mathbf{T}_{\mathbf{5 0} \%}$ : temperature where polymers reach $50 \%$ of weight loss; poly(catechol) 1: obtained by catalysis with native laccase; poly(catechol) 2: obtained by catalysis with PEGylated laccase; poly(catechol) 3: obtained by catalysis with epoxy-PEGylated laccase).

\begin{tabular}{llll}
\hline & $\mathrm{T}_{5 \%}\left({ }^{\circ} \mathrm{C}\right)$ & $\mathrm{T}_{50 \%}\left({ }^{\circ} \mathrm{C}\right)$ & Residual weight $\left(700{ }^{\circ} \mathrm{C}\right.$, wt \% $)$ \\
\hline Catechol & 147.89 & 201.56 & 0.55 \\
Poly(catechol) 1 & 118.02 & 345.06 & 37.55 \\
Poly(catechol) 2 & 122.85 & 414.28 & 42.45 \\
Poly(catechol) 3 & 120.51 & 437.80 & 40.14 \\
\hline
\end{tabular}
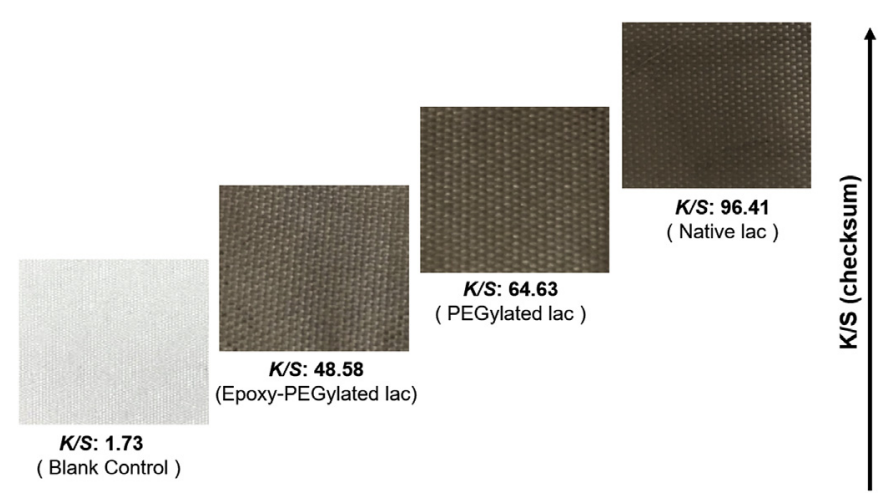

Fig. 5. PET samples after coloration with the poly(catechol) polymerized by enzymatic catalysis under high-pressure homogenization.

\section{Conclusions}

We found that the enzymatic catalysis using PEGylated and epoxy-PEG laccase, under high-pressure homogenization gave rise to longer polymers with particle sizes between 30 and $60 \mathrm{~nm}$. The small particle size obtained, especially when native laccase form was used, favored the coloration of a fiber which, in theory, would not be easily colored by these compounds. High-pressure homogenization revealed to be an effective technique for the enzymeassisted polymerization of catechol. Comparing with other processing methods, hydrodynamic cavitation promoted by the highpressure homogenizer provides a greener approach for catechol oxidation since it is energy efficient, chemical saving with low costs associated.

The green technology for catechol oxidation is reinforced by the use of laccase as biological catalyst working under mild reactions conditions of $\mathrm{pH}$ and temperature without addition of chemicals, using only atmospheric oxygen as electron source for oxidation.

The work presented herein is a step forward the green coloration of synthetic substrates by in situ enzymatic oxidation of phenolic compounds. Our results present polymers obtained enzymatically as valuable tools for the green coloration of fibers at lower temperatures. Further exploitation of the synergism between laccase and high-pressure homogenization technique will allow to obtain a vast palette of colors by oxidation of different concentrations of phenolic monomers.

\section{Funding}

This study was supported by the Chinese Government Scholarship under China Scholarship Council [grant No. 201606790036]; and by the Chinese Foundation Key projects of governmental cooperation in international scientific and technological innovation [grant No. 2016 YFE0115700]; and by the Portuguese Foundation for Science and Technology (FCT) under the scope of the strategic funding of UID/BIO/04469/2013 unit and COMPETE 2020 (POCI-010145-FEDER-006684) and BioTecNorte operation (NORTE-01-0145FEDER-000004) funded by European Regional Development Fund under the scope of Norte2020 - Programa Operacional Regional do Norte.

This work was also supported by the European Union through the European Regional Development Fund under the Competitiveness Operational Program [grant COP-A1.1.4-E-2015 nr.30/ 01.09.2016]; and by the Project "Search-ON2: Revitalization of HPC infrastructure of UMinho” [grant NORTE-07-0162-FEDER-000086), co-funded by the North Portugal Regional Operational Programme (ON.2 - O Novo Norte), under the National Strategic Reference 
Framework (NSRF), through the European Regional Development Fund.

The work was also supported by the FCT- Fundação para a Ciência e a Tecnologia [grant SFRH/BD/121673/2016 and grant IF/ 00186/2018].

\section{Appendix A. Supplementary data}

Supplementary data related to this article can be found at https://doi.org/10.1016/j.jclepro.2018.08.205.

\section{References}

Aghapour, A.A., et al., 2013. Biological degradation of catechol in wastewater using the sequencing continuous-inflow reactor (SCR). J. Environ. Health Sci. Eng. 11 (1), 3 .

Aktaș, N., et al., 2003. Biosynthesis and characterization of laccase catalyzed poly(Catechol). J. Polym. Environ. 11 (3), 123-128.

Aktas, N., Tanyolac, A., 2003. Reaction conditions for laccase catalyzed polymerization of catechol. Bioresour. Technol. 87.

Cheng, M., et al., 2018. Metal-organic frameworks for highly efficient heterogeneous fenton-like catalysis. Coord. Chem. Rev. 368, 80-92.

Cheng, M., et al., 2016. Degradation of atrazine by a novel fenton-like process and assessment the influence on the treated soil. J. Hazard Mater. 312, 184-191.

Childs, R.E., Bardsley, W.G., 1975. The steady-state kinetics of peroxidase with 2,2'azino-di-(3-ethyl-benzthiazoline-6-sulphonic acid) as chromogen. Biochem. J. 145 (1) 93-103.

Cohen, S., et al., 2009. Characterization of catechol derivative removal by lignin peroxidase in aqueous mixture. Bioresour. Technol. 100 (7), 2247-2253.

Daly, S.M., et al., 2005. Adsorption of poly(ethylene glycol)-modified lysozyme to silica. Langmuir 21 (4), 1328-1337.

Datta, S., et al., 2013. Enzyme immobilization: an overview on techniques and support materials. 3 Biotech 3 (1), 1-9.

Delgado-Povedano, M.M., Luque de Castro, M.D., 2015. A review on enzyme and ultrasound: a controversial but fruitful relationship. Anal. Chim. Acta 889, 1-21.

Diaz Blanco, C., et al., 2009. Dyeing Properties, Synthesis, Isolation and Characterization of an in Situ Generated Phenolic Pigment, Covalently Bound to Cotton.

Dubey, S., et al., 1998. Enzymatic synthesis and various properties of poly(catechol). Enzym. Microb. Technol. 23 (7-8), 432-437.

Faure, E., et al., 2013. Catechols as versatile platforms in polymer chemistry. Prog. Polym. Sci. 38 (1), 236-270.

Gall, V., et al., 2016. Extending applications of high-pressure homogenization by using simultaneous emulsification and mixing (SEM) - an overview. Processes 4 (4), 46.

Gogate, P., et al., 2006. Cavitation: a Technology on the Horizon.

Gogate, P.R., Pandit, A.B., 2000. Engineering design methods for cavitation reactors II: hydrodynamic cavitation. AlChE J. 46 (8), 1641-1649.

Goncalves, I., et al., 2014. Sonochemical and hydrodynamic cavitation reactors for laccase/hydrogen peroxide cotton bleaching. Ultrason. Sonochem. 21 (2), $774-781$.

Gupta, M.N., Roy, I., 2004. Enzymes in organic media. Forms, functions and applications. Eur. J. Biochem. 271 (13), 2575-2583.

Henriksson, M., et al., 2007. An environmentally friendly method for enzymeassisted preparation of microfibrillated cellulose (MFC) nanofibers. Eur. Polym. J. 43 (8), 3434-3441.

Jeon, J.R., et al., 2012. Laccase-catalysed oxidations of naturally occurring phenols: from in vivo biosynthetic pathways to green synthetic applications. Microb. Biotechnol. 5 (3), 318-332.
Jha, P.K., Halada, G.P., 2011. The catalytic role of uranyl in formation of polycatechol complexes. Chem. Cent. J. 5 (1), 12.

Jonsson, A., 2005. Public participation in water resources management: stakeholder voices on degree, scale, potential, and methods in future water management. Ambio 34 (7), 495-500.

Kim, S., et al., 2007. Laccases for enzymatic colouration of unbleached cotton. Enzym. Microb. Technol. 40 (7), 1788-1793.

Kozlowski, A., Milton Harris, J., 2001. Improvements in protein PEGylation: pegylated interferons for treatment of hepatitis C. J. Contr. Release 72 (1), 217-224.

Kudanga, T., et al., 2011. Potential applications of laccase-mediated coupling and grafting reactions: a review. Enzym. Microb. Technol. 48 (3), 195-208.

Kunamneni, A., et al., 2008. Engineering and Applications of fungal laccases for organic synthesis. Microb. Cell Factories 7.

Li, K., et al., 1999. Comparison of fungal laccases and redox mediators in oxidation of a nonphenolic lignin model compound. Appl. Environ. Microbiol. 65 (6) 2654-2660.

Liu, Y., et al., 2017. Effect of rhamnolipid solubilization on hexadecane bioavailability: enhancement or reduction? J. Hazard Mater. 322, 394-401.

Lobo, H., et al., 2013. Ultrasound-assisted Intensification of Bio-catalyzed Synthesis of Mono-N-alkyl Aromatic Amines.

Martins, M., et al., 2015. Stabilization of enzymes in micro-emulsions for ultrasound processes. Biochem. Eng. J. 93, 115-118.

Mayolo-Deloisa, K. et al., 2015. Aldehyde PEGylation of laccase from Trametes versicolor in route to increase its stability: effect on enzymatic activity. J. Mol. Recogn. 28 (3), 173-179.

Nabid, M.R., et al., 2010. Synthesis and characterization of poly(catechol) catalyzed by porphyrin and enzyme. Polym. Bull. 64 (9), 855-865.

Riva, S., 2006. Laccases: blue enzymes for green chemistry. Trends Biotechnol. 24 (5), 219-226.

Rodríguez Couto, S., Toca Herrera, J.L., 2006. Industrial and biotechnological applications of laccases: a review. Biotechnol. Adv. 24 (5), 500-513.

Romanski, F.S., et al., 2011. Important factors in the size reduction of polymerstabilized drug particle suspensions using high-pressure homogenization. J. Pharm. Innov, 6 (2), 97-106.

Saha, B., et al., 2011. Laccase-catalyzed removal of phenol and benzenediols from wastewater. J. Hazard., Toxic, Radioact. Waste 15 (1), 13-20.

Shah, S., Gupta, M.N., 2008. The effect of ultrasonic pre-treatment on the catalytic activity of lipases in aqueous and non-aqueous media. Chem. Cent. J. 2, 1-1.

Shinji, W., et al., 1993. Removal of phenols from wastewater by soluble and immobilized tyrosinase. Biotechnol. Bioeng. 42 (7), 854-858.

$\mathrm{Su}$, J., et al., 2018. The effect of high-energy environments on the structure of laccase-polymerized poly(catechol). Ultrason. Sonochem. 48, 275-280.

Su, J., et al., 2017. PEGylation greatly enhances laccase polymerase activity. ChemCatChem 9 (20), 3888-3894.

Tušek, A.J., et al., 2017. Catechol removal from aqueous media using laccase immobilized in different macro- and microreactor systems. Appl. Biochem. Biotechnol. 182 (4), 1575-1590.

Witayakran, S., Ragauskas, A.J., 2009. Synthetic applications of laccase in green chemistry. Adv. Synth. Catal. 351 (9), 1187-1209.

Yachmenev, V., et al., 2009. Acceleration of the enzymatic hydrolysis of corn stover and sugar cane bagasse celluloses by low intensity uniform ultrasound. J. Biobased Mater. Bioenergy 3 (1), 25-31.

Yachmenev, V.G., et al., 2002. Intensification of the bio-processing of cotton textiles by combined enzyme/ultrasound treatment. J. Chem. Technol. Biotechnol. 77 (5), 559-567.

Yang, C., et al., 2011. How PEGylation enhances the stability and potency of insulin: a molecular dynamics simulation. Biochemistry 50 (13), 2585-2593.

Yang, Z., et al., 2017. Effect of Membrane Electrode Assembly Design on the Cold Start Process of Proton Exchange Membrane Fuel Cells.

Zerva, A., et al., 2016. Bioconversion of biomass-derived phenols catalyzed by Myceliophthora thermophila laccase. Molecules 21 (5), 550. 